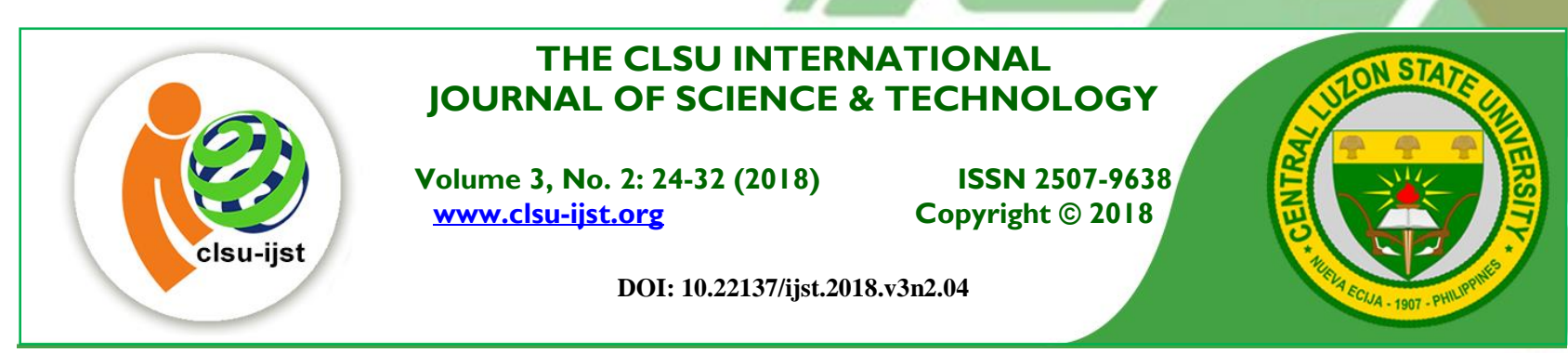

\title{
Mycelial Growth of Pink Oyster Mushroom (Pleurotus djamour) on Banana Sucrose Gulaman and Fruiting Body Production on Banana-Based Substrate Formulations
}

\author{
Lourilaine A. Silva ${ }^{1}$, Rich Milton R. Dulay ${ }^{1,2}$, Sofronio P. Kalaw ${ }^{1,2}$
}

${ }^{1}$ Department of Biological Sciences, College of Arts and Sciences, Central Luzon State University, Science City of Muñoz, Nueva Ecija, Philippines

${ }^{2}$ Center for Tropical Mushroom Research and Development, Central Luzon State University, Science City of Muñoz, Nueva Ecija, Philippines

*E-mail for correspondence: spk31162@,clsu.edu.ph

\section{ABSTRACT}

This study evaluated the mycelial growth of Pleurotus djamour on banana sucrose gulaman and fruiting body production on banana-based substrate formulations. Fruits of three local banana varieties, namely lakatan, latundan, and saba were used in the preparation of culture media. The mycelial growth and mycelial density were determined. Moreover, different banana-based substrate formulations such as $100 \%$ banana leaves, $75 \%$ banana leaves $+25 \%$ sawdust, $50 \%$ banana leaves + $50 \%$ sawdust, $25 \%$ banana leaves $+75 \%$ sawdust, and 100\% sawdust were evaluated. The rice strawbased substrate formulation consisting of $70 \%$ rice straw and 30\% sawdust was used as the control. Saba sucrose gulaman exhibited faster mycelial growth $(11.79 \mathrm{~mm} /$ day) and thick mycelial density. On the other hand, potato dextrose agar (control) recorded the smallest mycelial growth $(9.33 \mathrm{~mm} /$ day) and very thick mycelial density. Among the different substrate formulations, $70 \%$ rice straw $+30 \%$ sawdust (control) exhibited shorter incubation period (26.73 days) and shorter duration of primordial formation (28.93days). However, 50\% banana leaves $+50 \%$ sawdust exhibited highest yield (136.51 g) and highest biological efficiency $(19.50 \%)$.

Keywords: banana wastes, banana sucrose gulaman, biological efficiency, mycelial growth, pink oyster mushroom.

\section{INTRODUCTION}

Pleurotus djamour, commonly known as the pink oyster mushroom because of the pink color of the fruiting bodies, is a wood-rotting basidiomycetes which naturally grows as saprophyte on decaying logs of trees during rainy season. This exotic mushroom species was recently introduced in the country as an addition to the existing species of oyster mushrooms, namely Pleurotus florida, Pleurotus sajor-caju, Pleurotus cystidiosus, Pleurotus ostreatus, and Pleurotus pulmonarius. P. djamour is one of the widely distributed and commercially grown mushrooms in many countries. Apart from its high nutritional value and culinary importance, it is also a potential source of bioactive compounds with functional and pharmacological activities. For instance, the polysaccharide precipitate exhibited anti-tumor activity, 
while the fruiting bodies contain phytochemicals such as anthroquinones, flavonoids, saponins, tannins, and terpenoids (Borges et al. 2013; Sasidhara and Thirunalasundari 2014). Moreover, it also exhibited high DPPH radical scavenging activity, antibacterial property and hypolipidimic effect (Jegadeesh et al. 2014; Acharya et al. 2017; Dulay et al. 2017).

Banana is the number one fruit commodity in the Philippines both in terms of production and hectarage (Espino and Espino 2015). In 2015, the country produced nearly 9.1 million metric tons of bananas on 443,270 hectares of land (PSA 2015). This biennial herbaceous crop is primarily cultivated for its fruits. However, during its production, million metric tons of banana waste products are generated such as pseudo stems, leaves, stalks, rhizomes, and fruit peels (Padam et al. 2014). These untapped and neglected agricultural waste products when not properly managed can cause environmental hazards. Due to the lignocellulosic nature of these waste materials, they are potential substrates in cultivating different species of mushrooms. At present, the Central Luzon State University Mushroom Center for Research and Development (CTMRD) promotes the use of rice straw-based substrate formulation for growing various species of mushrooms. At present, dried banana leaves are being used as substrates in the production of paddy straw mushroom (Volvariella volvacea). Its potential use as substrate in growing oyster mushroom, particularly $P$. djamour has not been explored, thus this study.

\section{MATERIALS AND METHODS}

Pure culture of $P$. djamour obtained from the germplasm collection of the CTRMD, Central Luzon State University was revived using Potato Dextrose Agar. Approximately $10 \mathrm{~mm} 2$ mycelial block from the pure culture was aseptically inoculated to the center of an agar plate using a flamesterile inoculating needle. The inoculated plates were incubated at room temperature to allow mycelial growth and ramification.

\section{Evaluation of Different Varieties of Banana Used as Culture Medium}

In this experiment, the mycelial growth of $P$. djamour on three local varieties of banana, namely latundan, lakatan, and saba used as culture media was evaluated. Potato dextrose agar, a commercial medium was used as the control.

Preparation of banana sucrose gulaman. Banana sucrose gulaman (latundan, lakatan, and saba) was separately prepared by boiling 200 grams of sliced fruits, boiled in one liter of distilled water until cooked. The decoction was filtered to remove the banana and reconstituted to one liter by adding distilled water. Ten grams of white sugar and 20 grams of white gulaman bar were dissolved and mixed over low flame until the mixture is homogenous. This was dispensed into a flask plugged with cotton and covered with paper. The prepared media were sterilized in an autoclave at $121{ }^{\circ} \mathrm{C}, 15$ pound per square inch (psi) for 30 minutes.

Inoculation. Approximately $20 \mathrm{ml}$ of the medium was aseptically poured to a sterile petri plate and allowed to solidify overnight. A $10 \mathrm{~mm}$ mycelial disc from a seven-day old culture was aseptically inoculated onto each petri plate. The plates were incubated at room temperature to allow mycelial ramification. The mycelial diameter was measured after one week of incubation using digital Vernier caliper. The mycelial growth and mycelial density were determined. 


\section{Evaluation of Fruiting Body Performance of $\boldsymbol{P}$. djamour in Banana-based Substrate Formulations}

Preparation of grain spawn. Two kilograms of unmilled rice was boiled in four liters of water until tender. After boiling, the grains were air dried until $65 \%$ moisture content is attained. Forty grams of each spawn material was placed in a polypropylene bag with $5 \mathrm{~cm}$ PVC pipe at the top and plugged with cotton, wrapped with paper and sterilized by autoclaving at 15 psi or $121^{\circ} \mathrm{C}$ for 45 minutes. After sterilization and cooling, the grain spawn was inoculated with $10 \mathrm{~mm}$ mycelial disc from the pure culture of $P$. djamour and then incubated at room temperature to allow mycelial ramification.

Substrate preparation. Dried banana leaves were collected from the banana plantation in Central Luzon State University campus. The collected banana leaves were cut into smaller pieces using the multi-purpose shredder machine. The shredded leaves were then soaked in a water tank for three days. To remove the undesirable odor, the banana leaves were washed continuously with tap water and pulled out of the tank. These were transferred to the composting area and covered with plastic to create an anaerobic condition and to allow the growth of natural decomposers. After one week of composting, the substrate was formulated as follows: T1 - 100\% banana leaves, T2 - 75\% banana leaves $+25 \%$ sawdust, T3 $-50 \%$ banana leaves $+50 \%$ sawdust, T4 $-25 \%$ banana leaves $+75 \%$ sawdust, T5 $-100 \%$ sawdust, and T6 $-70 \%$ of rice straw $+30 \%$ sawdust (control). Seven hundred grams of the formulated substrates was placed and compacted in 6" x 12 " polypropylene bag. To serve as opening for the inoculum, each bag was inserted with a PVC pipe cuttings with $10 \mathrm{~cm}$ diameter, plugged with cotton and sealed with a rubber band. The fruiting bags were sterilized in an autoclave at $121^{\circ} \mathrm{C}, 15$ psi for one hour. The sterilized fruiting bags were allowed to cool down overnight. After cooling, 40 grams of grain spawn was inoculated on each fruiting bag and incubated at room temperature to allow mycelial running. Once fully ramified, the bags were transferred to the growing house and opened at one end to allow emergence of the fruiting bodies. The fruiting bags were watered three times a day using a pressurized sprinkler.

Statistical design and analysis. The experiment was laid out following the completely randomized design. Treatment means were compared Duncan Multiple Range Test. The data were analyzed using SAS statistical program.

\section{RESULTS AND DISCUSSION}

\section{Mycelial Growth $P$. djamour on Banana-based Substrate}

Culture media are important source of nutrients needed by mushroom organisms. At present semi-synthetic and indigenous culture media are being used for the mycelial cultivation of mushrooms. In mushroom production, availability, suitability, and cost are important consideration in selecting the medium to be used. In this study, banana-based culture media using different varieties were evaluated to determine the most suitable culture medium for optimum mycelial growth of $P$. djamour. Table 1 shows the mycelial growth and mycelial density of $P$. djamour on banana-based medium. It can be noted that saba sucrose gulaman recorded the highest mycelial growth with a mean of $11.79 \mathrm{~mm} /$ day. On the other hand, PDA (control) recorded the lowest mycelial growth of $9.33 \mathrm{~mm} /$ day. Statistical analysis revealed significant influence of the media on mycelial growth. The mycelial growth in potato dextrose agar is significantly smaller than the banana-based media. However, no significant difference was observed among the three banana-based media. In terms of mycelial density, $P$. djamour produced very thick and cottony mycelia in PDA (control), while cottony and thick mycelial growth was recorded in the three varieties (Figure 1).

\section{Vol. 3 No. 2 ISSN: 2507-9638 DOI: 10.22137/ijst.2018.v3n2.04}

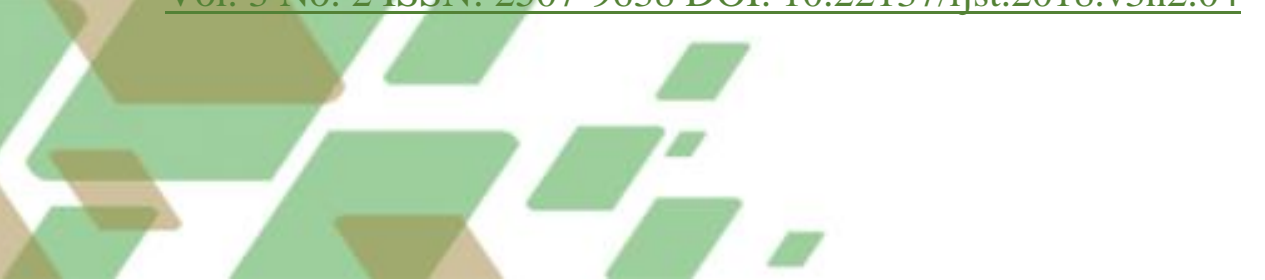


The result of the present study indicates that banana-based medium can support the mycelial growth of P. djamour. This could be due to the nutrient composition of banana fruits. USDA (2011) reported that bananas are a significant source of several vitamins and minerals, especially potassium, vitamin B6, and vitamin $\mathrm{C}$. They also contain vitamin A, B-vitamins (thiamine, $40 \mu \mathrm{g}$; riboflavin, $70 \mu \mathrm{g}$; niacin, $610 \mu \mathrm{g}$; pantothenic acid, $280 \mu \mathrm{g}$; pyrixodine, $470 \mu \mathrm{g}$; folic acid, $23 \mu \mathrm{g}$ ) and ascorbic acid (Aurore et al. 2009). Moreover, Egbebi and Bademosi (2012) disclosed that banana contains protein (3.15\%), ash (6\%), fat $(1.2 \%)$, crude fibre $(1.11 \%)$, sugar $(12.8 \%)$, carbohydrate $(27.24 \%)$, and total solid $(38.7 \mathrm{~g} / 100 \mathrm{~g})$.

Table 1. Mycelial growth and mycelial density of P. djamour on banana-based media

\begin{tabular}{lcc}
\hline Media & Mycelial growth (mm/day) & Mycelial Density \\
\hline Lakatan Sucrose Gulaman & $11.25^{\mathrm{a}}$ & +++ \\
Latundan Sucrose Gulaman & $11.25^{\mathrm{a}}$ & +++ \\
Saba Sucrose Gulaman & $11.79^{\mathrm{a}}$ & +++ \\
Potato dextrose Agar (control) & $9.33^{\mathrm{b}}$ & ++++ \\
\hline
\end{tabular}

Data presented are means of three replications. Means with the same letter are not significantly different at $5 \%$ level of significance using Duncan Multiple Range Test (DMRT). (+) very thin, $(++)$ thin, $(+++)$ thick, $(++++)$ very thick.

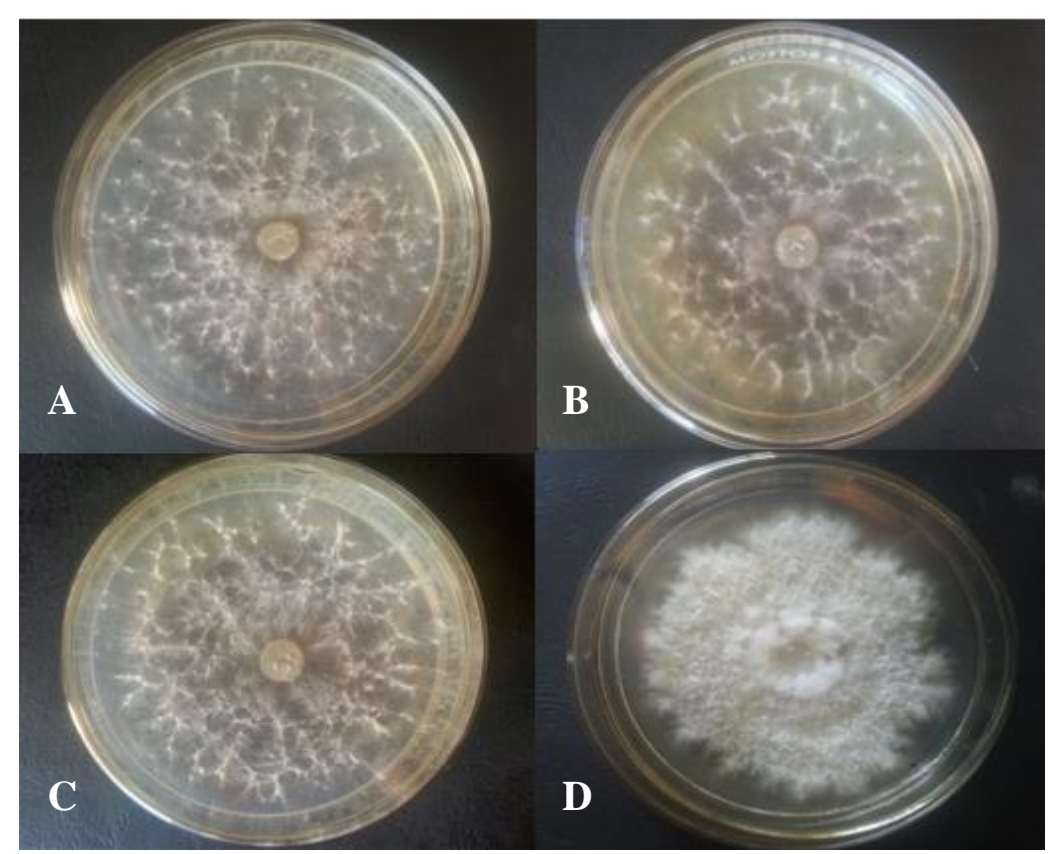

Figure 1. Mycelial growth of P. djamour on (A) lakatan sucrose gulaman, (B) latundan sucrose gulaman, (C) saba sucrose gulaman, and (D) potato dextrose agar on the $7^{\text {th }}$ day of incubation.

\section{Fruiting Body performance of $\boldsymbol{P}$. djamour in Banana-based Substrate Formulation}

Incubation period. The growth of mushrooms includes different phases such as mycelial colonization, primordial initiation, and fruiting body production. Incubation period refers to mycelial running from inoculation to the mycelial colonization of the substrate. Previous studies have reported that the incubation period varies according to the mushroom species, type of substrates, and formulation of the substrates (Chang and Miles 2004; Kalaw and Albinto 2015). Table 2 shows the incubation period of $P$. djamour on different banana based substrate formulations. It is interesting to note that the control (70\% rice straw: 30\% sawdust) recorded the shortest incubation period with a

\section{Vol. 3 No. 2 ISSN: 2507-9638 DOI: 10.22137/ijst.2018.v3n2.04}


mean of 26.73 days. On the other hand, the longest incubation period was recorded in $100 \%$ sawdust with a mean of 37.33 days. Analysis of variance revealed significant influence of substrate formulation on the incubation period. Findings of this study indicated that the incubation period is affected by the formulation of the substrates. The incubation period is shorter in substrate with lesser amount of saw dust while it is longer in substrate with $100 \%$ saw dust. This observation could be due to the compactness of the substrates. The smaller particle size of saw dust resulted to smaller pore spaces between the substrates which somehow made it difficult for the mycelial to penetrate the substrates that resulted to longer incubation period. A similar observation was reported by Bumanlag et al. (2018) in substrate formulation consisting of corn stalks and leaves mixed with different amount of saw dust. Chang and Miles (2004) reported that the difference in the duration of the incubation period in a given substrate could be due to the fungal strain, growth conditions, and substrate type. Moreover, Bhatti et al. (1987) explained that the variation could also be attributed to the difference in chemical composition and carbon nitrogen ration of the substrates. The incubation period obtained in the present study is shorter than the reported 40-48 days spawn run period Pleurotus species on compost bags by Obodai et al. (2003) but longer than 21 to 24.75 days complete mycelial running of $P$. florida on different substrates by Mondal et al. (2010).

Table 2. Incubation period and primordial formation of $P$. djamor on banana-based substrate formulation

\begin{tabular}{lcc}
\hline Treatments & Incubation Period (Days) & Primordia Formation (Days) \\
\hline $100 \% \mathrm{BL}$ & $27.18^{\mathrm{ed}}$ & $29.63^{\mathrm{d}}$ \\
$75 \% \mathrm{BL}+25 \% \mathrm{SD}$ & $28.67^{\mathrm{c}}$ & $31.92^{\mathrm{c}}$ \\
$50 \% \mathrm{BL}+50 \% \mathrm{SD}$ & $27.38^{\mathrm{d}}$ & $29.52^{\mathrm{d}}$ \\
$25 \% \mathrm{BL}+75 \% \mathrm{SD}$ & $32.15^{\mathrm{b}}$ & $34.14^{\mathrm{b}}$ \\
$100 \% \mathrm{SD}$ & $37.22^{\mathrm{a}}$ & $40.11^{\mathrm{a}}$ \\
$70 \% \mathrm{RS}+30 \% \mathrm{SD}$ (control) & $26.73^{\mathrm{e}}$ & $28.93^{\mathrm{d}}$ \\
\hline
\end{tabular}

Data presented are means of three replications. Means with the same letter are not significantly different at $5 \%$ level of significance using Duncan Multiple Range Test (DMRT).

$\mathrm{BL}=$ Banana leaves, $\mathrm{SD}=$ Saw dust and $\mathrm{RS}=$ Rice straw

Primordial formation. Primordial formation is the second stage of mycelial growth during cultivation of mushrooms. The duration of primordial initiation was determined from inoculation of the substrates to the appearance of primordia. The primordia are small pinhead-like structures growing in the fruiting bags. Table 2 shows the number of days required to primordial initiation in different substrate formulations. Substrate consisting of $70 \%$ rice straw $+30 \%$ sawdust recorded the shortest period with a mean of 28.93 days which is comparable to $100 \%$ banana leaves and $50 \%$ banana leaves and 50\% saw dust. On the other hand, 100\% sawdust recorded the longest duration with a mean value of 40.11 days. Analysis of variance revealed significant effect of substrate formulation on primordial formation. The values obtained in the present study are longer than the 22 days in Pleurotus ostreatus cultivated in banana pseudostem and leaves as reported by De Carvalho et al. (2012). Tirky et al. (2017) observed the primordial initiation of Pleurotus florida on 17th to 26th days. On the other hand, Mondal et al. (2010) disclosed that the primordia of Pleurotus species appeared 5.50 days after the spawn running, while Samuel and Eugene (2012) noted 5.80 to 8.01 days duration of primordial initiation of Pleurotus ostreatus on different substrate formulations. Moreover, Shah et al. (2004) found that the primordia appeared 6 days after full ramification of the mycelia. The observed variations in the duration of primordial formation can be attributed to the substrate formulations and substrates used in cultivating the mushrooms.

\section{Vol. 3 No. 2 ISSN: 2507-9638 DOI: 10.22137/ijst.2018.v3n2.04}

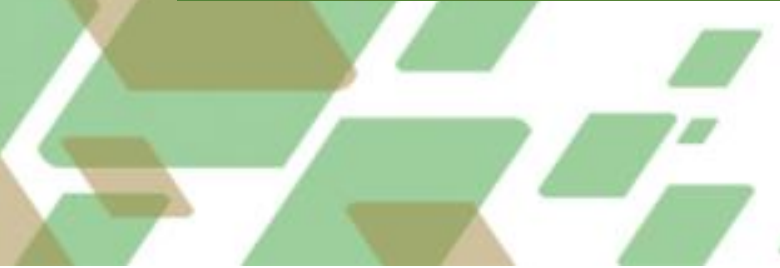


Yield. The yield in this study represents the weight of the fruiting bodies produced in two flushes. The total weight of fruiting bodies produced by $P$. djamour in different substrate formulations is presented in Table 3. Substrate formulation consisting of 50\% banana leaves $+50 \%$ sawdust recorded the highest yield with a mean of $136.51 \mathrm{~g}$. On the other hand, $25 \%$ banana leaves $+75 \%$ sawdust recorded the lowest yield with a mean of $85.25 \mathrm{~g}$ which is not statistically different from $100 \%$ sawdust. Analysis of variance revealed significant influence of substrate formulation on the yield. This finding indicates that $50 \%$ banana leaves and $50 \%$ saw dust is the best substrate combination to attain maximum yield. The observed variation in the yield in different substrate combination could be attributed to the difference in the nutrient composition of the formulated substrates. The values obtained in the present study are lower than the reported yield of two strains Pleurotus sajor-caju grown on rice straw-based substrate formulation by Villaceran et al. (2006) and five species of Pleurotus cultured on rice straw-based substrate formulations by Kalaw and Albinto (2015). However, the values are higher than the reported yield of Pleurotus pulmonarius cultivated in banana leaves by Adebayo et al. (2014). The results of the present study are consistent with the report of Moonmoon et al. (2010) that most of the growth, yield, and quality parameters varied significantly when mushrooms were cultivated with different levels of formulation. Magday et al. (2014) disclosed that the yield and biological efficiency of Ganoderma lucidum were significantly affected not only by pure sawdust but also by its combination with rice straw. Hoa et al. (2015) reported that Pleurotus ostreatus and Pleurotus cystidiosus grown on different substrate formulation consisting of corn cobs and sawdust showed significant difference in term of mushroom yield and biological efficiency. They explained that differences in terms of yield and biological efficiency of both oyster mushrooms grown on different substrate types were due to the differences in physical and chemical composition of substrate formulations such as cellulose/lignin ratio and mineral contents.

Table 4. Yield and biological efficiency of $P$. djamour

\begin{tabular}{lcc}
\hline Treatments & Total yield $(\mathrm{g})$ & Biological efficiency $(\%)$ \\
\hline $100 \% \mathrm{BL}$ & $99.27^{\mathrm{bc}}$ & $14.18^{\mathrm{bc}}$ \\
$75 \% \mathrm{BL}+25 \% \mathrm{SD}$ & $112.33^{\mathrm{b}}$ & $16.02^{\mathrm{b}}$ \\
$50 \% \mathrm{BL}+50 \% \mathrm{SD}$ & $136.51^{\mathrm{a}}$ & $19.50^{\mathrm{a}}$ \\
$25 \% \mathrm{BL}+75 \% \mathrm{SD}$ & $85.25^{\mathrm{d}}$ & $12.18^{\mathrm{c}}$ \\
$100 \% \mathrm{SD}$ & $88.72^{\mathrm{cd}}$ & $12.68^{\mathrm{c}}$ \\
$70 \% \mathrm{RS}+30 \% \mathrm{SD}$ (control) & $108.07^{\mathrm{b}}$ & $15.44^{\mathrm{b}}$ \\
\hline
\end{tabular}

Data presented are means of three replications. Means with the same letter are not significantly different at $5 \%$ level of significance using Duncan Multiple Range Test (DMRT).

$\mathrm{BL}=$ Banana leaves, $\mathrm{SD}=$ Saw dust and $\mathrm{RS}=$ Rice straw

Biological efficiency. Apart from the yield, biological efficiency is another important parameter to be considered in mushroom production. It is a measure of substrate conversion into mushroom fruiting bodies (Oseni et al. 2012). This parameter is used to evaluate the efficiency of substrate conversion in mushroom cultivation (Girmay et al. 2016). In this study, the biological efficiency was computed as the ratio of fresh weight of mushroom and weight of the substrate. The percentage of biological efficiency of $P$. djamour on different substrate formulations is also presented in Table 4. Substrate formulation consisting of $50 \%$ banana leaves $+50 \%$ sawdust recorded the highest biological efficiency with a mean of $19.50 \%$. On the other hand, $25 \%$ banana leaves $+75 \%$ sawdust recorded the lowest biological efficiency with a mean of $12.18 \%$. Analysis of variance revealed significant influence of substrate formulation on the biological efficiency. The biological efficiency varied significantly among the different substrates formulations evaluated. This could be due to the difference in the amount of nutrients present in the different substrate formulations and carbon and nitrogen ratio. The

Vol. 3 No. 2 ISSN: 2507-9638 DOI: 10.22137/ijst.2018.v3n2.04

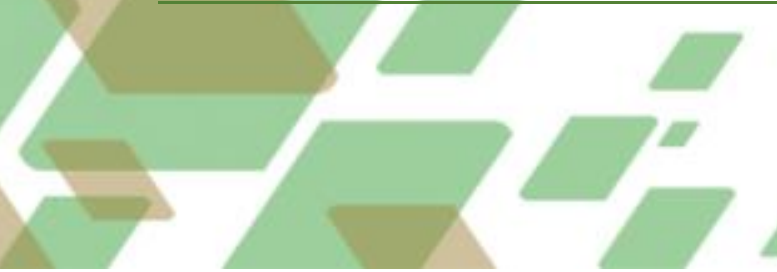


results obtained in the present study are lower than the reported $18.9 \%$ biological efficiency of Pleurotus pulmonarius grown in banana leaves by Adebayo et al. (2014) and P. djamour (31.1\%) cultivated in substrate consisting of rice straw, coconut peat, and rice bran by Zurbano et al. (2017). Furthermore, Tirkey et al (2017) reported 91\% biological efficiency of P. florida grown in banana leaves. Significant variations in biological efficiency of mushrooms cultivated on different substrates formulations have been previously reported (Liang et al. 2009; De Leon et al. 2014; Adebayo et al. 2014; Girmay et al. 2016). The significant difference in biological efficiency could be due to the differences in the nutrient composition, physical and chemical composition and C: $\mathrm{N}$ ratio of the substrates (Obodai et al. 2011; Hoa et al. 2015).

\section{REFERENCES}

Acharya, K., S. Khatua S, and S. Ray S. 2017. "Quality Assessment and Antioxidant Study of Pleurotus djamor (Rumph. ex Fr.) Boedijn." Journal of Applied Pharmaceutical Science 7(6): 105-110.

Adebayo, E. A. , M. B. Alao, O. O. Olatunbosun, E. O. Omeleye, and O.B. Omisakin. 2014. "Yield Evaluation of Pleurotus pulmonarius (Oyster Mushroom) on Different Agricultural Wastes and Various Grains for Spawn Production.” Ife Journal of Science 6(3): 475-480.

Aurore, G., B. Parfait, and L. Fahrasmane. 2009. "Bananas-Raw Materials for Making Processed Food Products." Trends in Food Science Technology 20:78-91.

Bhatti, M. A., F. A. Mir, and M. Siddiq.1987. "Effect of Different Bedding Materials on Relative Yield of Oyster Mushroom in the Successive Flushes." Pakistan Journal of Agricultural Research 8: 256-259.

Borges, G. M., F. F. De Barba, A. P. Schiebbelbein, B. P. Pereira, M. B. Chaves, M. L. Silveira, M. S. Pinho, and E. Wisbeck. 2013. "Extracellular Polysaccharide Production by a Strain of Pleurotus djamor Isolated in the South of Brazil and Antitumor Activity on Sarcoma 180." Brazil Journal of Microbiology 44:1059-1065.

Bumanlag, C. P. B., S. P. Kalaw, R. M. R. Dulay, and R. G. Reyes. 2018. "Optimum Conditions for Mycelial Growth and Basidiocarp Production of Pleurotus djamour on Corn-based Media." International Journal of Biology, Pharmacy and Allied Sciences. 7(4): 558-575.

Chang, S. T. and P. G. Miles. 2004. Mushroom Cultivation, Nutritive Value, Medicinal Effect, and Environmental Impact. $2^{\text {nd }}$ ed. USA: CRC Press.

De Carvalho, C. S. M., L. V. D. De Aguilar, C. Sales-Campos, Minhoni, M. T. A. Marli, and M. C. N. De Andrade. 2012. "Applicability of the Use of Wastes from Different Banana Cultivars for Cultivation of the Oyster Mushroom.” Brazilian Journal of Microbiology 43 (2): 819-826

Dulay, R. M. R., L. A. Miranda, J.S. Malasaga, S. P. Kalaw, R. G. Reyes, and C. T. Hou. 2017. "Antioxidant and Antibacterial Activities of Acetonitrile and Hexane Extracts of Lentinus tigrinus and "Pleurotus djamour." Biocatalysis and Agricultural Biotechnology 9:141-144.

De Leon, A. M., R. G. Reyes, and T. T. E. De La Cruz. 2014. "Lentinus squarrosulus and Polyporus grammocephalus: Newly Domesticated, Wild Edible Macrofungi from the Philippines." Philippine Agricultural Scientist 96(4):411-418. 


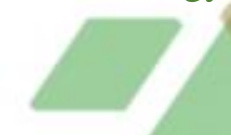

Egbebi, A. O. and T. A. Bademosi. 2012. "Chemical Composition of Ripe and Unripe Banana and Plaintain." International Journal of Tropical Medicine and Public Health 1(1):1-5.

Espino, R. R. C. and M. R. C. Espino. 2015. “The Status of the Fruit Industry in the Philippines.” Food and Fertilizer Center for the Asian and Pacific Region. Taipei, Taiwan. http: www.fftc.agnet.org/library.php?func $=$ view\&id $=20150810090507$

Jegadeesha, R., N. L. Raamana, V. Hariprasatha, Rameshc, and R. Srikumarc. 2014. "Hypolipidemic Effect of Pleurotusdjamor var. roseus in Experimentally Induced Hypercholesteromic Rats." Research Journal of Pharmaceutical, Biological, and Chemical Sciences 5(2):581-588.

Hoa, H. T., C. L. Wang, and C. H. Wang. 2015. “The Effects of Different Substrates on the Growth, Yield, and Nutritional Composition of Two Oyster Mushrooms (Pleurotus ostreatus and Pleurotus cystidiosus)." Mycobiology. 43 (4):423-34.

Girmay, Z., W. Gorems, G. Birhanu, and S. Zewdie. 2016. "Growth and Yield Performance of Pleurotusostreatus (Jacq. Fr.) Kumm (oyster mushroom) on Different Substrates." AMB Express 6(1): 87.

Kalaw, S. P. and R. F. Albinto. 2015. "Growth Performance and Nutritional Attributes of Pleurotus species Grown on Rice Straw-based Formulations." Advances in Environmental Biology 9(18):72-81.

Liang, Z. C., C. Y. Wu, Z. L. Shieh, and S. L. Cheng. 2009. "Utilization of Grass Plants for Cultivation of Pleurotuscitrinopeleatus." International Biodeterioration and Biodegradation 63(4):509-514.

Magday, J. C., M. E. Bungihan, and R. M. R. Dulay. 2014. "Optimization of Mycelial Growth and Cultivation of Fruiting Body of Philippine Strain of Ganodermalucidum." Current Research in Environment and Applied Mycology 4(22):162-172.

Mondal, S. R., M. J. Rehana, M. S. Noman, and S. K. Adhikary. 2010. "Comparative Study on Growth and Yield Performance of Oyster Mushroom (Pleurotus florida) on Different Substrates." Journal of Bangladesh Agricultural University 8(2):213-220.

Moonmoon, M., N. S. Shelly, M. A. Khan, M. A. Uddin, K. Hossain, M. Tania, and S. Ahmed. 2010. "Effects of Different Levels of Wheat Bran, Rice Bran, and Maize Powder Supplementation with Saw Dust on the Production of Shiitake Mushroom (Lentinusedodes (Berk.) Singer)." Saudi Journal of Biological Sciences 18: 323-328.

Obodai, M., J. Cleland-Okine, and K. Vowoto. 2003. "Comparative Study on the Growth and Yield of Pleurotusostreatus mushroom on Different Lignocellulosic By-products." Journal of Indian Microbiology and Biotechnology 30:146-149.

Oseni, T. O., S. S. Dube, P. K. Wahome, M. T. Masarirambi, and D. Earnshaw. 2012. "Effect of Wheat Bran Supplement on Growth and Yield of Oyster Mushroom (Pleurotus Ostreatus) on Fermented Pine Sawdust Substrate." Experimental Agriculture and Horticulture: 30-40.

Padam, B. S., H. S. Tin, F. Y. Chye, and M. I. Abdullah. 2014. "Banana By-products: An Under-utilized Renewable Food Biomass with Great Potential." Journal of Food Science and Technology 51 (12): 35273545.

\section{Vol. 3 No. 2 ISSN: 2507-9638 DOI: 10.22137/ijst.2018.v3n2.04}


Philippine Statistics Authority. 2015. Selected Statistics on Agriculture. Philippines: Philippine Statistics Authority.

Sasidhara, R. and T. Thirunalasundari. 2014. "Phytochemicals and Antioxidant Potentials of Pleurotus djamour." Journal of Chemical and Pharmaceutical Research 6(4):950-953.

Samuel, A. A. and T. L. Eugene. 2012. "Growth Performance and Yield of Oyster Mushroom (Pleurotus Ostreatus) on Different Substrates Composition in Buea South West Cameroon." Science Journal of Biochemistry 2012: 1-6. doi: 10.7237/sjbch/139.

Shah, Z. A., M. Ashraf, nd M. Ishtiaq. 2004. C"omparative Study on Cultivation and Yield Performance of Oyster Mushroom (Pleurotus ostreatus) on Different Substrates (Wheat Straw, Leaves, Saw Dust)." Pakistan Journal of Nutrition 3 (3):158-160.

Tirkey, V. J., S. Simon, and A. A. Lal. 2017. "Efficacy of Different Substrates on the Growth, Yield, and Nutritional Composition of Oyster Mushroom, Pleurotus florida (Mont.) Singer." Journal Pharmacognosy and Phytochemistry 6(4):1097-1100.

United States Department of Agriculture. 2011. "United States Department of Agriculture Agricultural Research Service National Nutrient Database for Standard Reference Release 28." https://ods.od.nih.gov/pubs/usdandb/Zinc-Content.pdf

Villacera, A. B., S. P. Kalaw, P. S. Nitural, E. A. Abella, and R. G. Reyes. 2006. "Cultivation of Thai and Japanese Strains of Pleurotus sajor - caju on Rice Straw-based Volvariella volvacea Mushroom Spent and Composted Rice Straw in Central Luzon Region, Philippines." Journal of Agricultural Tecbnology. 2(1):69-75.

Zurbano, L. Y., A. D. Bellere, L. C. Savilla. 2017. "Mycelial Growth, Fruiting Body Production, and Proximate Composition of P. Djamour on Different Substrates." The CLSU International Journal of Science and Technology 2(1): 20-30. 